6. Жизнь Алтая. - 1911.-13 февр. (№ 35). - Из содерж.: разд. «Корреспонденция» : [С. УстьЧарышская пристань Бийскаго уезда]. - С. 4.

7. К празднованию юбилея Отечественной войны. - Текст : непосредственный // Жизнь Алтая. 1912. - 23 авг. (№ 188), - С. 4.

8. Очевидец [псевд]. Наши торжества. - Текст : непосредственный // Жизнь Алтая. - 1912. - 28 авг. (№ 192). - С. ...

9. Весёлый [псевд.]. Детский вечер. - Текст : непосредственный // Жизнь Алтая. - 1913. - 25 янв. (№ 21). - С. 4.

10. До-ре : [псевд.]. Ученические вечера.-Текст : непосредственный // Жизнь Алтая. - 1914. 20 февр. (№ 40). - С. 3 .

11. Постоянный зритель [псевд.]. Театр и музыка. - Текст : непосредственный // Жизнь Алтая. 1914. - 8 янв. (№ 5). - С. 3.

12. [Анонс]. - Текст : непосредственный // Барнаульские ежедневные телеграммы. - 1903. - 5 нояб. (№ 242). - C. 1 .

Valerii A. Vinogradov

Altai State Institute of Culture, (Barnaul, Russia) vva1951@yandex.ru

\title{
MUSICAL AND THEATRICAL LIFE IN ALTAI MINING DISTRICT ON PAGES OF SIBERIAN PRE-REVOLUTIONARY PRESS
}

\begin{abstract}
The article gives results of the author's reconstruction of development of musical and theatrical life in Altai (in particular, the Altai Mining District (one of administrative units in the Russian Empire in 1834-1896) and Altai District (an administrative units in the Russian Empire in 1890-1917)) using materials of Siberian prerevolutionary press. The author notes the local finest people's high interest to stage performances and amateur musical activities. The paper considers historical context of appearance of authorities' attention to issues of cultural work in areas located far from administrative center of the Altai Mining District which included the today's Russian Altai Krai, Novosibirsk, Kemerovo, Tomsk Oblasts, republics o Altai, Khakassia, and East-Kazakhstan Oblast of the modern Kazakhstan. The contribution of Siberian pre-revolutionary papers to supporting of local initiatives in musical and theatrical life is stressed out. Also, the author concludes: scientific research in history of musical and theatrical life of Altai has a perspective significance for understanding of achievement of the past and the present of provincial cultural life in historical and the modern Russia.

Key words: Altai Mining District, Siberian pre-revolutionary press, musical life, theatrical life, stage performance, musical performance, a list of stage productions, road tour, charity.
\end{abstract}

УДК 39:008(470+571)=512.1:069.02

DOI: $10.32340 / 2414-9101-2019-3-36-42$

Т. И. Кимеева, кандидат культурологии, доцент Кемеровский государственный институт культуры (Кемерово, Россия) tat-kimeeva@mail.ru

\section{ЭТНОКУЛЬТУРНОЕ НАСЛЕДИЕ КОРЕННЫХ НАРОДОВ ПРИТОМЬЯ В МУЗЕЯХ РОССИИ}

\begin{abstract}
Аннотация. Представлен анализ объектов этнического культурного наследия коренных малочисленных народов Притомья (шорцев и бачатских телеутов), находящихся на хранении в фондах музеев России. Традиционная культура этих народов в естественной среде своего бытования, по мнению автора, значительно руинирована: в частности, констатируется безвозвратная утрата уникальных ремёсельных методик и технологий народных промыслов, специфических знаний в области культовой обрядности этнических сообществ и др. Охарактеризован потенциал музейных коллекций предметов народной культуры шорцев и бачатских телеутов в контексте презентации и популяризации этнических традиций коренных народов современного Кузбасса; культурное наследие коренных малочисленных народов рассматривается автором в качестве ценного ресурса развития этнокультурного туризма в регионе.
\end{abstract}


Ключевые слова: коренные малочисленные народы Сибири, иоризы, бачатские телеуты, этнокультурное наследие, традиционная этническая культура, музеи, музейные коллекичи, Кемеровская область.

Притомье - территория проживания шорцев и бачатских телеутов - автохтонного населения края, имеющего статус коренных малочисленных народов РФ. Обеспечение трансляции традиционной культуры этих народов с уникальными культурами таежных охотников-собирателейрыболовов и потомков скотоводов Южной Сибири создаст возможность привлечения притока в регион категорий туристов, настроенных на аутентичность культуры и знакомство с подлинными объектами этнокультурного наследия.

Объекты традиционной культуры шорцев и бачатских телеутов в условиях современности утрачены в среде бытования и представляют собой уникальный пласт этнокультурного наследия, овеществленные компоненты которого сохраняются в виде музейных предметов. На основе исследования этих предметов с привлечением музейных архивов возможно осуществление реконструкции нематериальных объектов культурного наследия - домашних ремёсел, в процессе которых создавались предметы традиционной культуры, а также сезонных и культовых обрядов, проведение которых предусматривало наличие овеществлённых компонентов, т. е. музейных предметов.

Самые ранние материалы, собранные на территории Кузнецкого уезда поступили в музеи Санкт-Петербурга и Омский музей, созданный по инициативе Западно-Сибирского отдела Императорского Русского географического общества (далее - ЗСО ИРГО) в 1882 г. В отчёте ЗСО ИРГО имеются сведения о посещении Н. М. Ядринцевым г. Кузнецка и приобретении там этнографических материалов $[1$, с. 7,18$]$. На заседании Отделения этнографии им упомянуты также обследования телеутов в Томском округе «близ Бочата» [2, с. 3]. Имеются данные о сборе этнографических материалов А. В. Адриановым в 1881 г. по улусам Кондомы и верховий Мрассу [3, с. 90]. Здесь им были приобретены предметы древних родовых культов шорцев, хранящиеся в настоящее время в фондах Российского этнографического музея Санкт-Петербурга. Из экспедиции 1883 г. в районы Каргинского стана Алтайской миссии и на Кабырзу А. В. Адрианов привёз этнографические материалы, часть которых передана в музей ЗСО ИРГО и впоследствии утрачена, о чем сохранились сведения в архиве Омского государственного историко-краеведческого музея (далее-ОГИКМ) [4, с. 8].

Одной из ранних по времени сбора и поступления в музей ЗСО ИРГО (ОГИКМ) является шорская коллекция С. П. Швецова, руководителя экспедиции по статистико-экономическому обследованию районов Горного Алтая в 1887 г. Предметы данной коллекции представляют собой уникальные объекты этнокультурного наследия: декорированные культовые предметы, включающие шаманские атрибуты и ритуальную утварь; элементы снаряжения охотника; курительную утварь из дерева и рога; предметы игр и ухода за ребенком; элементы костюма; украшения.

Уникальные предметы по традиционной культуре шорцев и бачатских телеутов были переданы в музеи Санкт-Петербурга в первом десятилетии XX в. исследователем шаманизма А. В. Анохиным, собравшим их в улусах по рекам Томи, Кондоме, Мрассу, в телеутском улусе Чолухой Томского уезда Кузнецкой губернии. Это - предметы родовых культов, шаманские бубны, декорированная берестяная утварь, игрушки, декорированный текстиль.

Научный интерес к культуре аборигенов Саяно-Алтая обусловил в I четверти XX в. организацию экспедиций в Кузнецкий уезд. В 1920-е гг. Н. П. Дыренкова, Л. Э. Каруновская, А. Г. Данилин, Л. Б. Панек и А. Е. Ефимова совершили ряд поездок в места компактного проживания шорцев и бачатских телеутов, результатом которых стало поступление в Музей антропологии и этнографии Ленинграда (далее - МАЭ) значительных собраний по традиционной культуре этих народов. В 1929 г. в улусе Челукой (Чолкой) была приобретена редкая коллекция образцов плетения из кожаных ремней, солонка из капа в виде барана, образцы плетения из тальника, предметы родового и шаманского культов, ритуальное покрывало, коллекция кукол для детских игр и др. Материалы А. Г. Данилина пополнили коллекцию и другого сибирского музеяАлтайского государственного краеведческого музея (далее-АГКМ), основанного в 1823 г. в г. Барнауле как ведомственный «Горный музеум». Среди поступлений были материалы, собран- 
ные А. Г. Данилиным в улусе Челухоево Кузнецкого уезда: украшенная декоративной простежкой, редкая в телеутских коллекциях «купайка»; декорированные кантом суконные чулки; образцы текстильных предметов, выполненные в технике лоскутной мозаики, традиционные пуговицы, старинные серьги.

Коллекции начала 1930-х гг. МАЭ отличает не совсем обычный для практики музейных поступлений характер. Их собиранию содействовали организационные мероприятия, с одной стороны - Академии наук, с другой - правительственных учреждений страны: Госконторы по новым видам экспорта (Новоэкспорт). Основными собирателями коллекций МАЭ по культуре шорцев и бачатских телеутов в нач. 1930-х гг. были А. В. Анохин, А. И. Новиков, Н. П. Дыренкова. Невостребованные для продажи сборы Новоэкспорта были приобретены МАЭ и частично - Музеем истории религии. Среди них антропоморфные культовые предметы, шаманские бубны, декорированные предметы из бересты и текстиля, редкие в коллекционных сборах по шорцам вышитые растительным орнаментом кожаные сапоги и подвязки для обуви, украшения; бубны телеутских шаманов с деревянными декорированными геометрической резьбой рукоятями.

Шорская коллекция Государственного музея этнографии народов СССР (ныне - Российский этнографический музей) сформирована из собранных в 1934 г. материалов Л. П. Потапова и А. К. Супинского в ходе экспедиции в Северную Шорию. Оба исследователя были связаны с научной деятельностью этого учреждения и благодаря им в музее появились такие редкие для музейных собраний предметы, как биовальные (двухголовые) идолы шорцев «тайгам».

Объекты этнокультурного наследия шорцев рассредоточены также и в основанных в I четверти XX в. музеях Юга Западной Сибири, где они находят фрагментарное отражение в экспозиционно-выставочной деятельности. Это можно сказать о шорских коллекциях г. Томска. В Губмузей (ныне - Томский областной краеведческий музей) культовые предметы, шаманская атрибутика, элементы костюма, собранные в Кузнецком уезде, поступили в $1923-1924$ гг. от 3. С. Гайсина, возглавлявшего в это время данный музей.

С 1925 по 1930-е гг. формируется коллекция по культуре шорцев на основе сборов А. К. Иванова для музея Томского университета. Привезённые А. К. Ивановым материалы отражают наличие у шорцев ремёсел, в рамках которых создавались предметы из рога марала и кости, декорированные контурной и сквозной геометрической резьбой деревянные рукояти шаманских бубнов, детские игрушки, декорированный текстиль, дополняющие костюм украшения, орнаментированные стрелы, сосуды для хранения культовых предметов с тиснённым сюжетномифологическим декором.

Отдельные предметы, характеризующие традиционную культуру шорцев и бачатских телеутов, появляются в фондах Музея истории и культуры народов Сибири и Дальнего Востока Института археологии и этнографии Сибирского отделения Российской академии наук как результат участия новосибирских этнографов Е. М. Тощаковой в этнографической экспедиции 19651969 гг. и А. П. Погожевой - в 1978 г. Обследовалась традиционная культура бачатских телеутов в деревнях Верховская, Бачаты, Беково Беловского района Кемеровской области. В фонды поступили женские рубахи-платья с вышитыми воротниками, праздничный халат, пояс, единственная в своем экземпляре среди телеутских материалов расшитая пуговицами головная повязка, нашивные украшения, серебряные и пластмассовые пуговицы, серебряные серьги, культовые предметы.

Формируются в 1970-70-е гг. шорская и телеутская коллекции в другом вузовском музее Музее археологии и этнографии Омского государственного университета из материалов этнографических экспедиций, совершенных под руководством А. Н. Томилова в поселки по Мрассу. Коллекция состоит из предметов, отражающих культовую деревянную резьбу, художественную обработку металла и декорирование предметов женской одежды.

Наряду с вывозимыми за пределы области материалами, отмечается формирование в 1920-е гг. коллекций, которые в настоящее время составляют часть собраний краеведческих музеев Кемеровской области - Новокузнецкого и Кемеровского. Начало коллекции Новокузнецкого краеведческого музея (далее-НКМ) было положено кузнецким краеведом-любителем Д. Т. Ярославцевым. Известно, что собранные им предметы представлялись на выставках различного уровня. Так, в 1923 г. самые уникальные образцы были отправлены в Москву на Всероссийскую выставку [5]. В 1924 г. в Томском краевом музее были зарегистрированы этнографические 
материалы Д. Т. Ярославцева, при этом общая численность шорской коллекции насчитывала 67 предметов [6, с. 28]. В настоящее время предметы из ранних сборов Д. Т. Ярославцева 1910-20-х гг. представлены в музее единично, так как они не были возвращены с выставок. Однако Новокузнецкий краеведческий музей обладает уникальными материалами, собранными Д. Т. Ярославцевым, такими как декорированная геометрической контурной и прорезной резьбой рукоять шаманского бубна и собственно бубен, датированные концом XIX в. Основателем краеведческого музея в Кузнецке считается Г. С. Блынский, оказывающий поддержку Д. Т. Ярославцеву. Его собрания в НКМ содержат культовые предметы, среди которых уникальный деревянный идол «арсан пӱрӱк кан сарай» с навершием-выступом на голове, в отличие от других изображений деревянной скульптуры, о лицетворящий духов охоты, ориентирован на защиту от духов болезни жилища и усадьбы в целом («арсан»- остерегаться болезней, пӥрйк/пӧрйк» - шапка [7, с. 17, 145], «кан» - социальный статус персонажа, «сарай» - один из вариантов перевода с кыпч., уйгур.: «дом» [8]) и другие невоспроизводимые в настоящее время предметы. Конец 1920-х гг. характеризуется сбором шорских материалов для музея Кузнецка известным краеведом К. А. Евреиновым, передавшим в музей декорированные медными пластинами по кожаной поверхности предметы; уникальный экземпляр шубы «Тон», вышитой цветными нитками. Телеутская коллекция НКМ немногочисленна, но представляет интерес в плане изучения таких женских ремесел, как плетение декоративных шнуров, тканье поясов и вышивка элементов женской рубахи «кунек», нагрудника «тӧштӧк», мужских - кузнечества, связанного с изготовлением серебряных украшений.

Последующие поступления в музей Сталинска, в который был переименован Кузнецк в 1932 г., зафиксированы только в послевоенные годы, самыми значительными из которых является переданная коллекция К. А. Евреинова, собранная им в ближних к городу шорских поселках. С 1950 по 1959 гг. сотрудники Сталинского краеведческого музея, ставшего Новокузнецким краеведческим музеем после переименования Сталинска в 1961 г. в Новокузнецк, совершают поездки по пригородным поселкам Новокузнецка, Междуреченска и др. (Абагур, Ольжерас, Учул).

Начало формирования собрания по традиционной культуре шорцев в Кемеровском краеведческом музее (далее - КОКМ) было положено открытием в городе Щегловске музея по инициативе «местного краеведческого общества» в 1929 г. Тогда же в здании Дворца Труда Щегловска, где экспонировались материалы музея, произошел пожар, и часть предметов пострадала. Относительно шорской коллекции этого периода известно, что «в запасниках музея находилась богатейшая коллекция по быту и верованиям шорцев» [8]. Ареал сбора музейных предметов включает улусы по Кондоме и её притокам (Красный Калтан, Турла, Чушла), по Мрассу и её притокам (Мыски, Усть-Кабырза, Парушка, Парлагол, Колхозный Карчит, Верхний Алзак, Эльбезе). Можно предположить, что хранящаяся в КОКМ уникальная коллекция старинных декорированных предметов из рога марала, была собрана именно в данный период в отмеченных поселениях. К сборам нач. XX в., несомненно, относятся предметы родовых и шаманских культов шорцев и бачатских телеутов. В коллекции зафиксированы неизвестные в других музеях России деревянные антропоморфные идолы, имеющие мифическое воплощение. В телеутской коллекция КОКМ представляют интерес элементы украшений традиционного костюма - нагрудники женских рубах, воротники, съемные украшения из серебряных и медных сплавов.

Коллекции по традиционной культуре коренных малочисленных народов Кемеровской области несколько позднее формировались также и в музеях других городов. Первой половиной $\mathrm{XX}$ в. датированы сборы Ф. И. Александрова и его сподвижников, благодаря стараниям которыХ в 1959 г. открыт Гурьевский городской краеведческий музей (далее-ГГКМ). Этнографическая коллекция ГГКМ, отражает целый ряд направлений народного декоративного искусства бачатских телеутов: резьбу по дереву; культовую роспись по коже шаманских бубнов; декорирование текстиля галуном и шнуром, характерной только для бачатских телеутов вышивкой «акча» и сферическими пуговицами «топчы»; плетение из конского волоса девичьих накосных украшений; тканье поясов, в декоре которых отражено почитание радуги «солонгы». Значимой частью коллекции являются украшения из серебряных сплавов - серьги «ызырга» со сферическими подвесками или низками бусин; женские накосники «тана» с серебряной основой и пуговицы «топчы» кустарного кузнечного производства; серебряные перстни с припаянным щитком, инкрустиро- 
ванным пуговицами мануфактурного производства, поделочным камнем или пастой. Представляет интерес скульптурная резьба по дереву, аналогов которой нет в других музеях России.

В 1960-е гг. по инициативе М. Г. Елькина был создан Прокопьевский городской краеведческий музей (далее-ПГКМ). Значительная часть коллекции была собрана сотрудником ПГКМ Н. А. Юшиной в рамках подготовки к созданию экспозиции «Этнографическая карта Сибири». Среди утилитарных предметов быта, охотничьего снаряжения представлены рубахи с традиционной вышивкой и коваными серебряными пуговицами, простеженные халаты, домотканые пояса, декорированные воротники и нагрудники, кожаная декорированная обувь бачатских телеутов и фурнитура для украшения элементов костюма, серьги, перстни и пуговицы с использованием серебряных сплавов.

Небольшое собрание из культовых предметов, одежды шорцев, предметов быта сосредоточено в Осинниковском краеведческом музее. В основном они представляют собой сборы участников историко-этнографического лагеря «Кузбасс», созданного на базе исторического факультета Кемеровского пединститута в 1960-е гг. Экспедиции проводились с 1965 г. под руководством кузбасского краеведа Д.В. Кацюбы и включали обследование шорских поселков окрестностей Осинников, Междуреченска, Новокузнецка.

Мысковский историко-этнографический музей обладает шорской коллекцией из утилитарных предметов, преимущественно утвари. Его открытие состоялось в 2003 г., когда предметы традиционной культуры уже не воспроизводились и не потреблялись в среде бытования.

Значительную коллекцию удалось сформировать коллективу Музея этнографии и природы Горной Шории (далее - МЭП) в г. Таштагол. Решение о создании музея было принято в 1989 г. - в тот период времени, когда в среде бытования исчез целый ряд домашних ремесел шорцев.

С 1990 г. по настоящее время сотрудники МЭП совершают экспедиции в поселки Таштагольского и соседних районов для выявления объектов культурного наследия шорцев. Среди массового сбора утилитарных предметов быта, орудий производства и промыслов им удалось приобрести отдельные экземпляры, имеющие отношение к художественным ремеслам, изготовленные в начале - I четверти XX в.: роговые пряслица и кольца для нарт, огнива, плетки, образцы вышитых элементов костюма туеса для хранения культовых предметов.

Кроме государственных музеев в Кемеровской области в 1980-е г. формируются собрания ведомственных музеев. Так, значительная по составу и содержанию этнографическая коллекция сформирована в музее «Археология, этнография и экология Сибири» (далее - МАЭЭС) Кемеровского государственного универститета (далее - КемГУ). Её основы были заложены в начале 1980х гг. При этом основную часть собрания составили материалы по традиционной культуре шорцев и бачатских телеутов. Под руководством этнографа В. М. Кимеева в результате первой экспедиции 1980 г. этнографической группой отряда Южносибирской археологической экспедиции КемГУ было осуществлено экспедиционное обследование поселков по реке Мрассу: Усть-Анзас, Кезек, Камзас, Эльбезе, Адыаксы и Мрассу. В 1985-87 гг. материал собирался в поселениях по рекам Пызас: Чилису-Анзас, Бугзас и Ортон: Учас, Трехречье, Ильинка. В данный период времени объекты культурного наследия в среде бытования уже были преимущественно руинированы, поэтому коллекция состоит в основном из ещё сохраняемых наследниками культуры утилитарных предметов - орудий ремесел и промыслов, предметов утвари, недекорированных элементов костюма.

В эти же годы этнографической группой под руководством В. М. Кимеева собирается материал в телеутских поселках Беково, Шанда и др., составивший собрание МАЭЭС. Телеутские материалы характеризует наличие отдельных элементов народного декоративного искусства вышитых «акча» воротников женской одежды, обуви, домотканых орнаментированных горизонтальными полосками поясов «кур» и сшитых в технике лоскутной мозаики культовых покрывал «кӧжӧгӧ», накосника «тана», пуговиц «топчы» и сережек «ызырга» из серебряных сплавов.

Значимым явлением для МАЭЭС явилась передача части коллекции Д. В. Кацюбы, которая до начала 2000-х гг. имела статус личной коллекции собирателя. Её бесценной частью явились собранные в поселениях бачатских телеутов предметы одежды, украшенные старинными пуговицами и позолоченным галуном начала XX века, ритуальные покрывала, культовые предметы, из- 
готовленные в технике скульптурной резьбы. Огромной ценностью обладает набор предметов украшений из серебряных сплавов - пуговиц, перстней, сережек.

Благодаря активному использованию участниками экспедиции в ходе исследования методов описания и фотофиксации архив МАЭЭС в настоящее время насчитывает более двухсот уникальных фотографий, отражающих не только технологии производства объектов художественного наследия телеутов, но и их функционирование в качестве овеществленных компонентов традиционных обрядов.

В конце 1980-х гг. в Кемеровской области создается музей-заповедник «Томская Писаница» (далее-МЗТП), для формирования этнографических фондов которого часть предметов быта шорцев, собранных В. М. Кимеевым в 1990-1993 гг. в поселках среднего течения Мрассу (УстьАнзас, Кезек, Парушка, Челей) была передана в МЗТП, среди которых наряду с утилитарными предметами, имеются и уникальные, такие как образцы традиционной резьбы по дереву. Коллекция МЗТП включает также переданные Д. А. Функом культовые предметы телеутов и художественно оформленные элементы костюма.

В конце 1990-х гг. начинается создание второго музея, организованного в месте компактного проживания коренных малочисленных народов Кузбасса-Историко-этнографического музея «Чолкой» (далее - ИЭМЧ). В связи с тем, что для бачатских телеутов свойственна ревитализация - оживление традиций носителями культуры в естественной социокультурной среде, сотрудникам музея удалось собрать содержательную этнографическую коллекцию, отражающую культуру народа. Особенностью ИЭМЧ является презентация нематериального наследия в культурно-образовательной деятельности музея - воссоздание технологических процессов хозяйственной деятельности, традиционных культовых обрядов.

Особое место занимает формирование коллекции в экомузее «Тазгол», созданном на основе идеи французских теоретиков и не имеющем коллекции в традиционном понимании. Фонд формируется из предметов, которые ещё сохраняются у жителей поселков Усть-Анзас и Кезек, но имеют риск быть утраченными в естественной социокультурной среде. Предметы экспонируются в одном из объектов экомузея, однако они на сегодняшний день не включены в Государственный фонд Российской Федерации, но, возможно, впоследствии данная процедура будет осуществлена. На базе экомузея «Тазгол», также как в ИЭМЧ, имеются возможности для презентации технологий ремесел, обрядов и хозяйственной деятельности.

Таким образом, формирование музейных собраний предметами, характеризующими этнокультурное наследие коренных малочисленных народов региона, позволило сохранить для последующих поколений невоспроизводимые в настоящее время предметы, созданные в рамках художественных ремёсел шорцев и бачатских телеутов. Тенденцией современности является использование сосредоточенного в музейных собраниях и ставшего уникальным культурного наследия в культурно-образовательной сфере, в том числе и развивающегося в Кемеровской области туризма.

\section{Список литературы}

1. Отчёт Западно-Сибирского Императорского русского географического общества за 1978 год. Текст : электронный // Записки Западно-Сибирского Отдела Императорского Русского Географического общества. - Омск : Типогр. окружн. штаба, 1879-1916. - Кн. 1. - 1879. - IV, 229 с. разд. паг. : табл. - URL: http://www.prlib.ru/item/411910 (дата обращения: 12.03.2019).

2. Ядринцев, Н. М. Об алтайцах и черневых татарах : [читано в заседании Отделения этнографии 23го марта 1881 года]. - [Санкт-Петербург] : Типография В. Безобразова и К, [1881]. - 27 с. - Отд. оттиск из «Известий Имп. рус. геогр. о-ва», 1881, Кн. 17, вып. 4, с. 228-254. - URL: http://elib.tomsk.ru/purl/1-8742/ (дат обращения: 12.03.2019).

3. Усков, И. Ю. Становление Кузнецкого исторического краеведения. - Текст : непосредственный // Вестник Кемеровского государственного университета культуры. - 2015. - № 30. - С. 84-96.

4. Народы Южной Сибири в коллекциях Омского государственного объединённого исторического и литературного музея : [кат. этногр. кол.]. - Томск : Изд-во Томского гос. ун-та, 1990. - 201 с. - (Культура народов мира в этнографических собраниях российских музеев). - Текст : непосредственный.

5. Краткий отчёт предгубмузея 3. Гайсина, прибывшего из командировки в г. Щегловск, рудники Кемерово, Кольчугино, Бочаты, Прокопьево и гор. Кузнецк, - с 15 июля по 15 августа 1923 года. - Текст : не- 
посредственный // Архив Томского государственного объединённого историко-архитектурного музея. Оп. 1. - Д. 6. - Л. 293-294, 301.

6. Шатилов, М. Исторический очерк и обзор Томского краевого музея. - Текст : электронный // Труды Томского краевого музея. - Томск : [Красное знамя], 1927. - Т. 1 / под ред. М. А. Слободского, М. Б. Шатилова. - С. 1-38. - URL: https://www.elib.tomsk.ru/purl/1-694/ (дата обращения: 10.03.2019).

7. Шор казак пазок казак шор ӱргедик сӧстӱк: шорско-русский и русско-шорский словарь / сост. Н. А. Курпешко-Таннагашева, Ф. Я. Апонькин. - Кемерово : Кемеровск. кн. изд-во, 1993. - 149 с. - Текст : непосредственный.

8. Сарай : [происхождение слова]. - Текст : электронный // Этимологические онлайн словари русского языка. - 2019. - URL: https://lexicography.online/etymology/c/сарай (дата обращения: 06.09.2019).

9. Выдрина, О. В. К истории создания Кемеровского областного краеведческого музея. - Текст : электронный // Новосибирский архивный вестник : инф.-метод. бюллетень комитета гос. архивной службы ардминистрации Новосибирской обл. - Новосибирск : [б. и.], 1999. - № 2. - С. 58-63. URL: http://archive.nso.ru/sites/archive.nso.ru/wodby_files/files/page_102/nav_2.pdf (дата обращения: 10.03.2019).

Tatiana I. Kimeeva, Ph. D. in Cultural Studies, Associate Professor Kemerovo State Institute of Culture (Kemerovo, Russia) tat-kimeeva@mail.ru

\title{
ETHNIC AND CULTURAL HERITAGE OF INDIGENOUS PEOPLE OF PRITOME (WEST SIBERIA, RUSSIA) IN RUSSIAN MUSEUMS
}

\begin{abstract}
The article deals with analysis of items of ethnic and cultural heritage of indigenous peoples of Pritomie (Shors and Teleuts) stocked Russian museums. In natural environment, traditional culture of these peoples, on the author's opinion, is almost ruined: it is necessary to state a loss of unique handicrafts techniques, ethnic communities' peculiar knowledge about cult rituals, etc. The author outlines a potential of museum collections of Shors' and Teleuts' people's culture items in presentation and popularization of ethnic traditions of indigenous peoples of Kuzbass area; cultural heritage of indigenous peoples is considered by the author as a valuable resource for developing ethnic and cultural tourism in the region.
\end{abstract}

Key words: indigenous peoples in Siberia, Shors, Teleuts, items of cultural heritage, traditional ethnic culture, museums, museum collections, Kemerovo Oblast.

УДК 763:7.071.1Тырса:069.02:7(571.150)

DOI: $10.32340 / 2414-9101-2019-3-42-46$

О. В. Сидорова, кандидат исторических наук

Государственный художественный музей Алтайского края (Барнаул, Россия) semyasidorov@yandex.ru

\section{ИСТОРИЯ ОДНОЙ РАБОТЫ. ЛИТОГРАФИЯ НИКОЛАЯ ТЫРСЫ «НА ПЛЯЖЕ» (1939 Г.) ИЗ СОБРАНИЯ ГОСУДАРСТВЕННОГО ХУДОЖЕСТВЕННОГО МУЗЕЯ АЛТАЙСКОГО КРАЯ}

Исследование выполнено при финансовой поддержке РФФИ в рамках научного проекта № 19-412220003 «Экспликация потенциала художественной культуры Алтайского края и определения механизмов его использования в региональных и международных туристических проектах»

Аннотация. Государственный художественный музей Алтайского края (г. Барнаул Алтайского края, Россия) располагает значительной коллекцией произведений, выполненных мастерами ленинградской школы эстампа, среди которых особое место занимает Николай Андреевич Тырса (1887-1942 гг.) - известный советский художник и педагог. В статье представлен искусствоведческий анализ литографии Н. Тырсы «На пляже» (1939 г.), находящейся в собрании Государственного художественного музея Алтайского края; изложены факты, касающиеся истории её создания в экспериментальной мастерской при Ленинградском отделении Союза советских художников и появления в фондах музея. 